\section{An Economic Analysis of Soilless Culture in Gerbera Production}

\author{
I. Grafiadellis ${ }^{1}$ and K. Mattas ${ }^{2}$ \\ School of Agriculture, Department of Agricultural Economics, Aristotle \\ University of Thessaloniki, P.O. Box 225, 54006 Thessaloniki, Greece
}

E. Maloupa ${ }^{3}$

Agricultural Research Center of Macedonia and Thrace, P.O. Box 312, 57001

Thermi, Thessaloniki, Greece

\section{Tzouramani ${ }^{4}$ and K. Galanopoulos ${ }^{4}$}

Agricultural Economics and Social Research Institute, Kifissias 184C, 14562 Kifissia, Greece

Additional index words. culture system, greenhouses, floriculture, Mediterranean, Greece, Gerbera jamesonii

Abstract. The financial effectiveness of the soilless culture system (SCS) of gerbera (Gerbera jamesonii Bol. ex Adlam.) production was compared with that of the soil culture system in heated greenhouses in northern Greece. Evaluation was based on budgeting procedures that assumed a project life of 9 years. The decision to accept or to reject the investment was based on the following criteria: 1) net present value analysis (U.S. \$18,414), 2) benefit/cost ratio, and 3 ) risk exposure ratio. The soilless culture system, particularly the plastic bag system using perlite media, was more profitable. Application of sensitivity analysis illustrated the significance of product price and discount rate in determining the accrued benefits.

Over the last two decades, significant changes have occurred in the cultivation of high-value horticultural crops, as new production techniques have been introduced and evaluated. In principle, the enumeration and description of the inherent technical and horticultural advantages of a new technique should be accompanied by a thorough investigation of its economic efficiency. This evaluation procedure has evoked considerable attention, mainly because worldwide market liberalization has transformed the floriculture market into a highly competitive one. Nevertheless, few scientific analyses have been made of the economic effectiveness of new horticultural techniques. The introduction of the substrate has brought radical changes in protected ornamental production and has given producers the opportunity to achieve: 1) a high percentage of high-quality products, 2) uniform products, 3) total control of greenhouse production, 4) reduction of negative effects on the environment, and 5) significantly lower energy costs (Maloupa, 1993). Despite these advantages, the high initial investment cost of soilless culture and the need for extremely

Received for publication 20 Apr. 1998. Accepted for publication 8 July 1999. We gratefully acknowledge valuable comments and suggestions by three anonymous journal reviewers and the editors. The cost of publishing this paper was defrayed in part by the payment of page charges. Under postal regulations, this paper therefore must be hereby marked advertisement solely to indicate this fact.

${ }^{1} \mathrm{PhD}$ Candidate.

${ }^{2}$ Professor; to whom reprint requests should be addressed (e-mail: mattas@eng.auth.gr).;

${ }^{3}$ Senior Researcher.

${ }^{4}$ Researcher. skilled labor make producers reluctant to adopt this procedure (Sarooshi, 1987). Hence, farmers require a well-documented answer to the question of whether the cost of adoption of soilless cultivation in perlite exceeds the value of the investment in the long run.

Protected cultivation is an economically important enterprise in Greece, significantly contributing both to the individual farmer's income and to the national trade balance (Mattas et al., 1990). Horticultural and floriculture greenhouse production has increased $92.4 \%$ during the last 10 years (Tzouramani et al., 1995). Various flower crops are cultivated in greenhouses, but gerbera seems to be gaining importance in the European market.

The primary objective of the present study was to evaluate the economic feasibility of gerbera cultivation in heated greenhouses in northern Greece using the traditional soil culture system (TS) vs. the perlite soilless culture system in plastic bags (PSS).

\section{Materials and Methods}

Procedure. The experiment was conducted from June 1991 until May 1993 at the Agricultural Research Center of northern Greece in Thessaloniki, a semiarid Mediterranean region where the summer is hot and dry and the winter is cold and rainy. Costs of heating equipment and greenhouse construction were based on estimates by Salem (1992) and Tzouramani (1994).

The two systems were compared in two, round arch, single-span type plastic greenhouses of $150 \mathrm{~m}^{2}$, with vertical side walls (Tzouramani, 1994), which were heated by circulation of warm water in corrugated plas- tic tubes (Salem et al., 1993). The greenhouses were covered with a thermal polyethylene film. During winter (November to February), the temperature at night was kept above $12^{\circ} \mathrm{C}$; in summer, a black shading net was placed over the greenhouses. Further, in the PSS greenhouse the ground was covered with a white, 20 -mm-thick plastic film to improve light reflection.

Planting occurred on 15 June in both treatments. In the PSS greenhouse, perlite-filled polyethylene bags $0.15 \mathrm{~m}$ in diameter and 2.9 $\mathrm{m}$ long were placed end-to-end in double rows $0.50 \mathrm{~m}$ apart. Plants (12 per bag) were then planted in the medium at a spacing of $0.20 \times$ $0.25 \mathrm{~m}$ for a total of 6144 plants/0.1 ha. Four cultivars of gerbera ('Party', 'Fame', 'Regina', and 'Ximena') were used.

Each plant was irrigated by a dripper of nominal discharge at $2 \mathrm{~L} \cdot \mathrm{h}^{-1}$. A control unit regulated the delivery of nutrient solution on a daily basis. Water was applied for $2 \min 8$ to 16 times per day depending upon need. The solution was collected from the bottom of the medium and reused.

Traditional soil culture was used in the second greenhouse. Plants were planted in two-row beds separated by paths $0.40 \mathrm{~m}$ wide. Within-row spacing was $0.25 \mathrm{~m}$ and between row spacing $0.30 \mathrm{~m}$, giving an approximate density of six plants $/ \mathrm{m}^{2}$ (6144 plants/0.1 ha).

A 9-year project life was assumed. During this period, the investment would be productive without a major replacement. According to Helfert (1991), economic life is the length of time over which an investment yields economic benefits. However, after the 9 th year of economic life, essential high-cost components of the investment, such as heating system, irrigation system, thermal polyethylene cover, plastic bag system, substrate, plants, and plastic mulch, would have to be replaced. Thus, a 9-year time span can provide an accurate picture of the profits for the entire period of the project, assuming no unforeseen outlays or changes.

The real discount rate was set at $10 \%$, reflecting the current Greek financial market (Bank of Greece, 1995). Operating costs and output prices were assumed to increase incrementally at the same rate as inflation throughout the entire 9 years. Costs and benefits were estimated at 1995 prices. The currency unit was the U.S. dollar (235 Greek drachmas $=1$ U.S. dollar) (Bank of Greece, 1995).

Gross revenues and production for PSS and TS were evaluated and compared in order to determine the benefits provided by the adoption of PSS. Three appraisal criteria were used: 1) the net present value (NPV) (Levy and Sarnat, 1994a), 2) the benefit/cost ratio (B/C) (Gittinger, 1972), and 3) the risk-exposure ratio (RE-Ratio) (Gitman, 1977). Additionally, factors affecting the level of the income benefits were investigated by performing sensitivity analysis.

Economic assessment. Capital budgeting procedures are being used in modern finance theory to estimate yields on investments (Levy and Sarnat, 1994b; Papadopoulos, 1986). When evaluating alternative projects, expected costs and revenues should be estimated, and spe- 
cific selection criteria should then be employed (Horne and James, 1977). This approach, known as economic engineering, has been employed in evaluating new agricultural technologies (Feder et al., 1993; Food and Agriculture Organization of the United Nations, 1995; Lambregts et al., 1993).

The principle of incremental cash flows states that a project can be evaluated by considering all the incremental cash inflows and outflows induced by the investment (Levy and Sarnat, 1994c). This implies that costs and benefits "with" and "without" the investment must be compared to determine which alternative solution yields a higher return.

The net present value method (Levy and Sarnat, 1994a) can be defined algebraically by the following equation:

$$
\mathrm{NPV}=\sum_{\mathrm{t}=1}^{\mathrm{n}} \frac{\mathrm{S}_{\mathrm{t}}}{(1+\mathrm{r})^{\mathrm{t}}}-\mathrm{I}_{0}
$$

where $S_{t}=$ the expected net cash receipt at the end of year $\mathrm{t} ; \mathrm{I}_{0}=$ the initial outlay; $\mathrm{r}=$ the discount rate (the required minimum annual rate of return of new investment); $n=$ is expected life; and $\mathrm{t}=$ the project duration in years.

Furthermore, the use of multi-year NPV is based on the economic life of the project. Its sign can be positive or negative depending on whether there is a discounted net inflow or outflow over the economic life of the project (Helfert, 1991).

The $\mathrm{B} / \mathrm{C}$ ratio is the present value of the benefits relative to the present value of the costs (Gittinger, 1972). The decision rule is the following: 1 ) if $\mathrm{B} / \mathrm{C}$ ratio $>1$ or the $\mathrm{NPV}>0$, the project will be accepted and 2 ) if $\mathrm{B} / \mathrm{C}$ ratio $<1$ or the NPV $<0$, the project will be rejected (Pagoulatos, 1992).

Gitman (1977) developed a new ratio, the risk exposure-ratio (RE-Ratio), which, instead of assessing variability or dispersion, measures the degree of risk exposure present in a given capital expenditure alternative. The RERatio can be interpreted as representing the reduction in annual cash inflows (expressed as percentage of the net investment) that could be experienced annually and allow the project to remain acceptable. This ratio actually represents a linear transformation of a benefit/cost ratio. The specific form of RE-Ratio is given below:

$$
\mathrm{RE}-\text { Ratio }=\left(B / C^{-1}\right) *\left(\frac{1}{F_{k, n}}\right)
$$

where $\mathrm{B} / \mathrm{C}=$ benefit/cost ratio; and $\mathrm{F}_{\mathrm{k}, \mathrm{n}}=$ the factor for the present value of an n-year annuity discounted at $\mathrm{k}$ percent or:

$$
F_{k, n}=\frac{1}{(1+k)^{1}}+\frac{1}{(1+k)^{2}} \ldots \frac{1}{(1+k)^{1}}
$$

The decision rule for RE-Ratio is to accept all projects that exhibit positive RE-Ratios and NPV. When alternative techniques (projects) are assessed, projects with higher RE-Ratios should be selected. Therefore, RERatio can be used to measure project worth, and allows estimations of the degree of project risk exposure to be made (Gitman, 1977).

\section{Results and Discussion}

Production and gross returns. Production and gross returns of both the PSS and TS systems were estimated and compared for the experimental period of 24 months (Table 1). No distinctions among cultivars were considered and quality was assumed to be the same for both PSS and TS. Gross returns were computed using actual gerbera price data obtained from the local market.

Comparisons based on actual yield data clearly demonstrate that the annual average production of PSS exceeded the annual average production of TS by $5.1 \%$ (Table 1 ). Moreover, gross returns of the PSS were greater than those of TS by $6.6 \%$ (Table 1).

Production costs. Production costs were estimated for the 24-month period of the experiment, based on 0.1 ha. As was indicated earlier, the use of perlite as a substrate led to a differentiation in the operating cost between the two systems considered $(\$ 42,132$ and $\$ 40,930$ for PSS and TS, respectively) for an area of 0.1 ha (Table 1). The irrigation systems for the two cultivation systems differed substantially. The irrigation system was more complicated and therefore more costly for PSS, since the use of plastic bags required establishing a recirculation system for the nutrient solution (Table 1).

The use of the horizontal plastic bag method in PSS caused additional costs in comparison with the TS, and harvesting expenses were also greater in PSS because of higher production (Table 1).

Financial analysis. As mentioned earlier, three discounted measures (NPV, B/C Ratio, and RE-Ratio) were estimated to assess the economic efficiency of PSS vs. TS. Therefore, monetary flows of the two systems were considered (Table 2) and discounted at $10 \%$, within a period of 9 years (Table 3 ).

The NPV was $\$ 18,414$, and the $\mathrm{B} / \mathrm{C}$ ratio 3.3 for PSS. Both criteria indicate that the adoption of PSS increased income. In addition, the sufficiently large risk exposure-ratio of $41.3 \%$ obtained indicates clearly that the annual cash inflows may be reduced by $41.3 \%$ and the project can still maintain its positive NPV.

Sensitivity analysis. Sensitivity analysis offers both additional insights on the value of the investment analysis and an indication of how various factors can influence the derived outcomes (Pagoulatos, 1992). Furthermore, using sensitivity analysis a firm can best estimate all revenues and costs involved in a project by calculating the project's NPV and then checking the sensitivity of the NPV to possible estimation errors of the gross revenues and various cost items (Levy and Sarnat, 1994). In this study two important factors, the discount rate and the product price, were investigated by changing the range of values. A $50 \%$ decrease in the discount rate increased NPV by $38.2 \%$. Conversely, a $50 \%$ increase in the discount rate reduced NPV by $26.7 \%$ (Fig. 1 ). Hence, one can argue that any decline in the discount rate cannot significantly affect the outcome. Since the discount rate reflects the macroeconomic conditions, it cannot be influenced by producers; however, it can be intuitively argued that as the Greek economy is steadily improving, some spectacular changes can be expected.

Finally, NPV was very sensitive to product price variations. A price reduction of $50 \%$ reduced NPV $29.2 \%$, whereas a $50 \%$ price increase generated a $70.8 \%$ increase in NPV. In other words, product price is a crucial factor that can significantly affect the size of NPV. This clearly implies that producers can increase their income by implementing advanced production and marketing strategies that yield higher prices, such as early production or wellplanned timing of production, purchase contracts, and better packaging.

\section{Conclusions}

The use of SCS in gerbera production can substantially improve producers' income. However, financial analysis revealed that the PSS is more profitable than TS. Producers that adopted PSS earned an estimated net income of $\$ 18,414$ over 9 years. Sensitivity analysis revealed that income benefits can be further improved by even a minor increase in the product's price. High quality and better marketing strategies that lead to higher product price can also enhance investment benefits.

The results of this investigation support the conclusion that advances in technology may provide new opportunities for improving the overall efficiency of the greenhouse enterprise. However, further research on the effectiveness of PSS is needed to establish more concrete recommendations.

Table 1. Average annual production, costs, and gross returns for the traditional soil culture system (TS) vs. the soilless culture system (PSS) for gerbera on 0.1 ha over 24 months.

\begin{tabular}{lccc}
\hline \hline System & TS & PSS & Increase with PSS (\%) \\
\hline Production (no. flowers) & 178,729 & 187,955 & 5.2 \\
Returns (\$U.S.) & 59,631 & 63,564 & 6.6 \\
Costs (\$U.S.) & & & \\
$\quad$ Harvesting & 4,626 & 5,649 & 22.1 \\
$\quad$ Operating & 40,930 & 42,132 & 2.9 \\
$\quad$ Capital & 29,035 & 30,255 & 4.2 \\
Other & 851 & 1,277 & 50.1 \\
$\quad$ Total & 75,442 & 79,313 & 5.1 \\
Cost per flower & 12.27 & 12.90 & 5.1 \\
\hline
\end{tabular}


Table 2. Estimated costs of and revenues from (\$U.S.) the perlite soilless culture system (PSS) vs. the traditional soil culture system (TS) for gerbera on 0.1 ha for selected years.

\begin{tabular}{|c|c|c|c|c|c|c|c|c|c|c|}
\hline & \multicolumn{2}{|c|}{ Year 1} & \multicolumn{2}{|c|}{ Year 3} & \multicolumn{2}{|c|}{ Year 5} & \multicolumn{2}{|c|}{ Year 7} & \multicolumn{2}{|c|}{ Year 9} \\
\hline & $\mathrm{TS}$ & PSS & $\mathrm{TS}$ & PSS & $\mathrm{TS}$ & PSS & $\mathrm{TS}$ & PSS & $\mathrm{TS}$ & PSS \\
\hline \multicolumn{11}{|l|}{ Capital costs } \\
\hline Greenhouse structure & 12,766 & 12,766 & 0 & 0 & 0 & 0 & 0 & 0 & 0 & 0 \\
\hline PE-cover & 1,064 & 1,064 & 0 & 0 & 0 & 0 & 1,064 & 1,064 & 0 & 0 \\
\hline Heating system & 6,383 & 6,383 & 0 & 0 & 0 & 0 & 0 & 0 & 0 & 0 \\
\hline Irrigation system & 1,163 & 2,383 & 0 & 0 & 0 & 0 & 0 & 0 & 0 & 0 \\
\hline Operating costs & & & & & & & 0 & 0 & 0 & 0 \\
\hline Plastic bags & --- & 404 & --- & 404 & --- & 404 & --- & 404 & --- & 0 \\
\hline Plants & 7,843 & 7,843 & 7,843 & 7,843 & 7,843 & 7,843 & 7,843 & 7,843 & 0 & 0 \\
\hline Shading net & 1,277 & 1,277 & 0 & 0 & 0 & 0 & 1,277 & 1,277 & 0 & 0 \\
\hline Double glazing with a plastic film & 213 & 213 & 213 & 213 & 213 & 213 & 213 & 213 & 213 & 213 \\
\hline Plastic mulch & --- & 851 & --- & 0 & --- & 0 & --- & 851 & --- & 0 \\
\hline Perlite & --- & 1,004 & --- & 1,004 & --- & 1,004 & --- & 1,004 & --- & 0 \\
\hline Electricity & 25 & 37 & 43 & 64 & 43 & 64 & 43 & 64 & 17 & 27 \\
\hline Water & 22 & 20 & 38 & 34 & 38 & 34 & 38 & 34 & 16 & 14 \\
\hline Harvesting cost & 383 & 289 & 1,622 & 2,109 & 1,622 & 2,109 & 1,622 & 2,109 & 1,239 & 1,820 \\
\hline Insurance & 124 & 124 & 213 & 213 & 213 & 213 & 213 & 213 & 89 & 89 \\
\hline Other & 248 & 372 & 426 & 638 & 426 & 638 & 426 & 638 & 177 & 266 \\
\hline Total & 19,403 & 20,677 & 25,933 & 27,080 & 25,933 & 27,080 & 27,210 & 29,207 & 8,018 & 8,743 \\
\hline Total costs & 48,439 & 50,932 & 25,933 & 27,080 & 25,933 & 27,080 & 28,273 & 30,271 & 8,018 & 8,743 \\
\hline Salvage value & 0 & 0 & 0 & 0 & 0 & 0 & 0 & 0 & 14,925 & 15,047 \\
\hline Gross revenues & 16,693 & 12,917 & 64,625 & 73,572 & 64,625 & 73,572 & 64,625 & 73,572 & 47,932 & 60,655 \\
\hline Net benefits & $-31,745$ & $-38,015$ & 38,692 & 46,493 & 38,692 & 46,493 & 36,352 & 43,301 & 39,914 & 51,912 \\
\hline
\end{tabular}

Table 3. Estimated cash flow (\$U.S.) for the perlite soilless culture system (PSS) vs. the traditional soil culture system (TS), 0.1 ha.

\begin{tabular}{|c|c|c|c|c|c|c|c|c|c|c|}
\hline & \multicolumn{10}{|c|}{ Year } \\
\hline & 1 & 2 & 3 & 4 & 5 & 6 & 7 & 8 & 9 & Total \\
\hline Outflow & 2494 & 653 & 1147 & 1504 & 1147 & 1181 & 1998 & 653 & 725 & 11,504 \\
\hline Inflow & -3776 & 2852 & 8947 & 2852 & 8947 & 2852 & 8947 & 2852 & 12845 & 47,316 \\
\hline Discount factor ${ }^{2}$ & 0.909 & 0.826 & 0.751 & 0.683 & 0.621 & 0.564 & 0.513 & 0.467 & 0.424 & 5.759 \\
\hline Discounted cash outflow & 2268 & 540 & 862 & 1028 & 712 & 667 & 1026 & 305 & 307 & 7,714 \\
\hline Discounted cash inflow & -3433 & 2357 & 6722 & 1948 & 5555 & 1610 & 4591 & 1330 & 5447 & 26,128 \\
\hline Discounted cash flow & -5700 & 1817 & 5860 & 920 & 4843 & 943 & 3566 & 1026 & 5140 & 18,414 \\
\hline
\end{tabular}

${ }^{2}$ Discount factor (D.F): The general form which was used in order to determine each year's discount factor was the following:

$\mathrm{q}(\mathrm{t}, \mathrm{k})=\frac{1}{(1+\mathrm{k})^{t}}$

where $\mathrm{t}$ denotes the year, and $\mathrm{k}$ the discount rate.

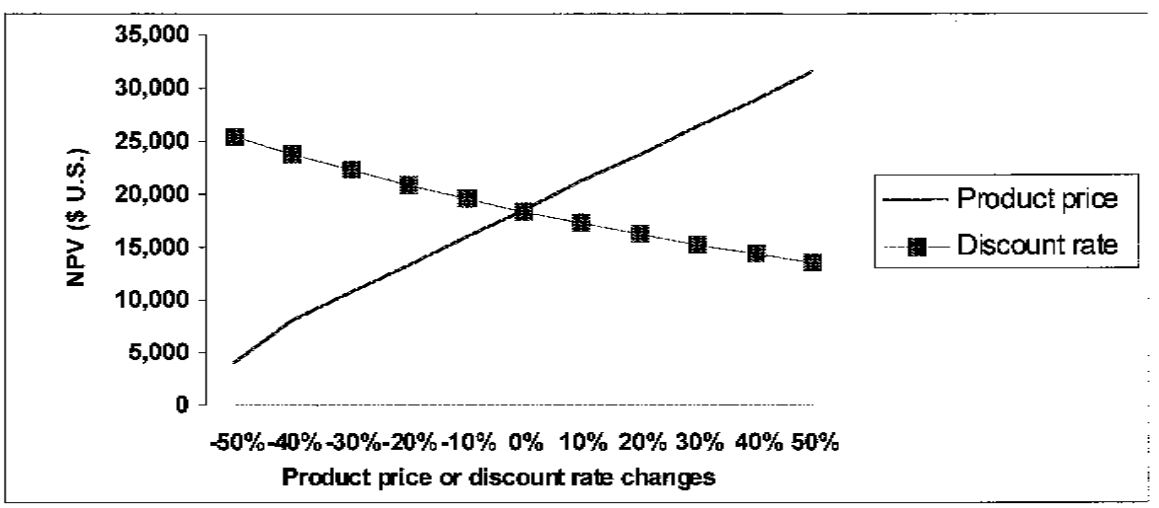

Fig. 1. The effects of a change in discount rate and product price on net present value (NPV) of gerbera grown on 0.1 ha.

\section{Literature Cited}

Bank of Greece. 1995. Monthly statistical bulletin. Bank of Greece, Athens.

Feder, G. and D. Umali, 1993. The adoption of agricultural innovations: A review. Technol. Forecasting and Social Change 43:215-239.

Food and Agriculture Organization of the United Nations. 1995. Guidelines for the design of agricultural investments projects, p. 112-113. FAO, Rome.

Gitman, L.J. 1977. Capturing risk exposure in the evaluation of capital budgeting projects. Eng. Economist 22:261-274.

Gittinger, J.P. 1972. Economic analysis of agricultural projects. 2nd ed. Intl. Bank for Reconstruction and Dev., Baltimore.

Helfert, E.A. 1991. Analysis of capital investment decisions, p. 211-277. In: R. Homewood and D. Irwin (eds.). Techniques of financial analysis, 3rd ed. Irwin, Boston.

Horne, V. and C. James. 1977. Financial management and policy. Prentice Hall, Englewood Cliffs, N.J.

Lambregts, J.A.D., W.L. Griffin, R.D. Lacewell, J.T. Davis, and G.M. Clary. 1993. Estimated 
costs and returns for catfish farms with recirculating ponds along the upper Texas coast. J. Agr Appl. Econ. 25(2), Dec. 1993:1-12.

Levy, H. and M. Sarnat. 1994a. The economic evaluation of investment proposals, p. 38-44, In: Capital investment and financial decisions. Prentice Hall, Hertfordshire, U.K.

Levy, H. and M. Sarnat. 1994b. Capital budgeting: An overview, p. 21-33. In: Capital investment and financial decisions. Prentice Hall, Hertfordshire, U.K.

Levy, H. and M. Sarnat. 1994c. Using cash flows to evaluate investments, p. 116-155. In: Capital investment and financial decisions. Prentice Hall, Hertfordshire, U.K.
Maloupa, E. 1993. Hydroponic culture of floricultural crops under protected cultivation in Mediterranean conditions. Proc. Natl. Mtg. for Hort. Crops under Protected Cultivation. Heraclio, Crete.

Mattas, K., M. Grafiadellis, E. Papanagiotou, and M. Martica. 1990. Evaluating the effectiveness of the passive solar system for heating greenhouses. Acta Hort. 263: 97-101.

Pagoulatos, A. 1992. Investment project analysis. Training Material Intl., Lexington, Ky.

Papadopoulos, D. 1986. Financial analysis of capital investments of the enterprise (in Greek). Paratiritis, Thessaloniki, Greece.

Salem, A. 1992. Economic evaluation of a passive solar greenhouse heating system. MS Thesis, Mediterranean Agron. Inst. of Chania, Greece. Salem, A., K. Mattas, and M. Grafiadellis. 1993. Assessing low-cost input use in off-season tomato production. Acta Hort. 340:117-124.

Sarooshi, R. 1987. Hydroponic growing of strawberries, p. 93. In: Proc. Hydroponics Wkshp., Salamander Bay, NSW, Australia, 16-18 Mar. 1987.

Tzouramani, I. 1994. Investment alternatives in greenhouse enterprises. MS Thesis, Mediterranean Agron. Inst. of Chania, Greece.

Tzouramani, I., K. Mattas, and M. Grafiadellis. 1995. Directing farmers' greenhouse construction decisions. Medit 6(2):44-48. 